\title{
Modelo de taller de lectura científica: "Soldados de Salamina", novela y filme
}

Scientific reading workshops: a model and an example

\author{
José LÓPEZ YEPES \\ Universidad Complutense de Madrid \\ yepes@ccinf.ucm.es
}

\begin{abstract}
Resumen
La lectura es un acto intelectual en el que se produce la descodificación de ciertos signos a fin de conocer lo que significan. La lectura científica, estadio avanzado de la lectura, tiene por objeto el conocimiento de la veracidad y trascendencia del texto o, dicho de otro modo, la llamada interpretación y crítica de las fuentes es el acto intelectual que permite la interpretación correcta de lo leído bajo los condicionantes de tiempo, espacio y persona. El concepto de fuente hace referencia a la información vinculada estrechamente con los acontecimientos o hechos objeto de estudio o reconstrucción, información cuyo valor se basa en las notas de originalidad, veracidad y autenticidad. Se propone un modelo didáctico de lectura científica para estudiantes del grado de Información y Documentación, que se ejemplifica con la novela y película "Soldados de Salamina".
\end{abstract}

Palabras clave: Lectura científica. Aprendizaje. Estudiantes universitarios. Enseñanza. Información y Documentación.

\section{La nociónd de lectura científica}

La lectura científica, estadio avanzado de la lectura, tiene por objeto el conocimiento de la veracidad y trascendencia del texto o, dicho de otro modo, la llamada interpretación y crítica de las fuentes es el acto intelectual que permite la interpretación correcta de lo leído bajo los condicionantes de tiempo, espacio y persona. (López Yepes, 2011ª, p. 79-80).

A nuestro entender, son objetivos de la lectura científica: a) discernimiento en profundidad y rigor del contenido del documento y su veracidad; b) aprendizaje en la capacidad de reflexión; c) aprovechamiento de las ideas que interesan al lector; e) instrumento que permite al lector, mediante su reflexión, obtener nuevas ideas en el ámbito de la investigación científica o percibir adecuadamente e impregnarse del contenido de las diversas disciplinas en el proceso de las enseñanzas; y f) desarrollo del espíritu crítico en el lector como manifestación del oficio del pensamiento.

\begin{abstract}
Reading is an intellectual act in which signs are decoded to find what they mean. Scientific reading is an advanced stage of reading that is aimed at assessing the transcendence and veracity of texts. In other words, the interpretation and criticism of sources is the intellectual act that ensures the right interpretation of texts, considering their times, spaces and the persons involved. Sources are defined as information that is closely connected with the events and facts that are being studied and reconstructed, and whose value rests on their originality, veracity and authenticity. A didactic model for teaching scientific reading to undergraduate students, which is exemplified with the Spanish novel and film "Soldiers of Salamina".
\end{abstract}

Keywords: Scientific reading. Learning. University students. Teaching. Library and information science.

\section{La lectura científica como base de reflexión para la obtención de conocimiento científico y de aprendizaje en la enseñanza universitaria}

Las nuevas ideas científicas procuradas por el investigador como soluciones a los problemas planteados en su investigación pasan por el siguiente proceso:

En primer lugar, el investigador no solo interpreta los mensajes de los documentos, sino que los integra en su propio texto, generando nuevos documentos y, por consiguiente, nuevos caminos de lectura crítica y nuevas interpretaciones.

En una segunda fase, en el acto de la interpretación, el investigador obtiene los siguientes tipos de ideas:

1. Las ideas claramente manifestadas en el texto que - tras discernir su veracidad o falsedad- le sirvan al investigador como apoyo para sustentar sus propias observaciones. 
2. Las ideas que, tan solo sugeridas por el autor, pueden ser aprovechadas por el investigador.

3. Las ideas que, de algún modo expuestas por el autor de la fuente, no cobraron valor en su momento por no existir el estado científico adecuado para ser proclamadas verdades científicas.

4. Las ideas propias que obtiene el investigador al comparar, relacionar y reflexionar sobre la materia ofrecida por la fuentes (López Yepes, 2011b).

El aprendizaje de la lectura crítica en universitarios se basa en alcanzar una serie de objetivos, válidos para cualquier disciplina, y comprende los siguientes:

1. Aprender a buscar y seleccionar fuentes valiosas de información.

2. Despertar en el alumno el espíritu crítico e investigador.

3. Ejercitar la práctica de la lectura científica teniendo como punto de partida los principios expuestos por Finkel (2008), según los cuales los alumnos aprenden pensando por ellos mismos, aprovechando las experiencias que la realidad, los libros y el profesor les muestran, y alcanzando, al fin, ideas y experiencias propias.

Como se sabe el comentario de textos es uno de los recursos que opera en los llamados talleres de lectura (Calleja, 2006, p. 322-336). En nuestro caso, un modelo de recurso didáctico para el aprendizaje de tal género de lectura crítica experimentado por los alumnos de la asignatura Documentación informativa (Grado de Periodismo, Facultad de Ciencias de la Información, Universidad Complutense de Madrid), se ha desarrollado como sigue:

1. Trabajo individual o colectivo.

2. Tema elegido por el profesor o los alumnos a partir de un documento audiovisual.

3. Estudio a partir de una metodología para la elaboración de trabajos individuales o colectivos de lectura crítica de acuerdo con las siguientes fases de trabajo:

3.1. Introducción. Planteamiento general y objetivos.

3.2. Selección de documentos textuales y audiovisuales para el estudio del tema.

3.3 Descripción del contexto histórico, geográfico, cultural, etc., contenido en los docu- mentos seleccionados (personajes, instituciones, acontecimientos, etc.)

3.4. Lista de las fuentes de documentación utilizadas en los documentos objeto de comparación.

3.5. Lista de cuestiones a tratar mediante el estudio de sus fuentes.

3.6. Estudio comparativo de las fuentes de documentación empleadas en los documentos (situaciones, argumentos, personajes, música, fotografía, etc. )

3.7. Uso de entrevistas personales a expertos en el tema, si procede.

3.8. Conclusiones y valoraciones personales (López Yepes, 2021b, p. 207-221).

Anexos: El trabajo debe complementarse con material complementarios como fotografías, videos, facsímiles de documentos, etc.

\section{Propuesta de taller de lectura: "Soldados de Salamina", Novela y filme}

En definitiva, la lectura científica es un instrumento imprescindible en la formación en criterios de verdad, en el desarrollo de la capacidad de investigación y en la formación de intelectuales, esto es, el oficio del pensamiento. La propuesta de taller de lectura que ofrecemos a continuación trata de obtener consecuencias del uso comparativo de las fuentes de documentación en una novela y en la película adaptada a la misma a fin de calibrar el valor de la lectura en ambos formatos desde el punto de vista de las fuentes documentales empleadas en ambos textos. En modo alguno se trata de llevar a cabo una crítica literaria o filmográfica.

Se parte de la sinopsis de la novela disponible en Wikipedia (Wikimedia contributors, 2012) y del texto de la novela disponible en Internet (Cerca, 2003). En el año 2002 se realiza una película basada en la novela, y con el mismo título, dirigida por el español David Trueba. Se han puesto a disposición de los alumnos fragmentos breves de la misma en el servidor de medios de la Universidad Complutense (http://complumedia.ucm.es). La película está también disponible en InternetEsto permitió trabajar ambos tipos de lenguaje -el textual y el fílmico-, enriqueciendo la experiencia.

El protagonista es Rafael Sánchez Mazas, que (Cercas, 2001, p. 59-60)

Había nacido en Madrid un 18 de febrero de hacía cuarenta y cinco años. Su padre, un médico militar oriundo de Coria, cuyo tío había sido médico de Alfonso XII, murió a los pocos meses, y la madre, 
María Rosario Mazas y Orbegozo, buscó de inmediato la protección de su familia en Bilbao. Allí, en una casa de cinco plantas situada junto al puente del Arenal, en la calle Henao, halagado por los mimos de un ejército de tíos sin hijos, transcurrieron su infancia y adolescencia [...]

\section{Fuentes de documentación utilizadas por el escritor y el director de cine}

La fuentes de la novela son las siguientes (Cercas, 2001):

1. Fuentes orales. Entrevistas. Hijos de Sánchez Mazas. Amigos del Bosque (p. 17 y 21).

2. Archivo y Filmoteca de Cataluña, p.16. "Recorrí bibliotecas, hemerotecas, archivos [....] Hablar con eruditos, con profesores, con amigos y conocidos [...]", "en cuanto acabe de documentarme", p. 29

3. Visita del autor a los lugares.

4. Diario de Sánchez Mazas (p. 23-24).

5. Archivo Histórico de Gerona.

Y las de la película se presentan a continuaciónn, según el minutado de la copia disponible en Internet (Trueba, 2003):

1. Documentales de la época, José Antonio, Franco y toma de posesión de Sánchez Mazas, combates en la guerra, José Antonio Primo de Rivera, Bombardeos de Madrid, padre, exilio, Machado (39.40/40.25).

2. Toma de posesión de Sánchez Mazas (7.42/10.40).

3. Documentales reconstruidos, barco Uruguay, huida de la población civil (43.15/44.42 y 45.01/46.50).

4. Obras de Sánchez Mazas, Biblioteca Nacional (20.40/22.59).

5. Recortes de prensa sobre Sánchez Mazas (idem).

6. Relato real de Sánchez Mazas (idem).

7. Entrevista con hijo de Sánchez Mazas (idem).

8. Fuentes orales: Los amigos del bosque, un hermano Figueras y un hijo de Figueras, Angelats, aldeano que informa del lugar de la ejecución (31.28/33.03). Quim, otro amigo del bosque (34.15/36.37, Archivo de Gerona), Los amigos del bosque (15.05/15.45).

9. Angelats (37.10/38.39).

10.Archivo Histórico de Gerona (idem).
11. Libreta que entrega Figueras hijo al periodista $(31.28 / 33.03)$.

12.Santuario, aldeano real que informa del sitio (48.40/56.12).

La naturaleza de "Soldados de Salamina", tanto en la novela como en la película, no está clara. De un lado, puede considerarse un reportaje periodístico elevado más tarde a versión de documental fílmico. Pero, de otro lado, la presencia de circunstancias y de personajes de ficción la elevan a la categoría de novela, tal vez, novela histórica, acepción nunca empleada por Cercas y por Trueba. En todo caso, ambos responsables buscaron afanosamente fuentes que les permitieran establecer la verdad de los hechos y sugerencias para llevar a cabo ambas obras.

\section{Lista de cuestiones a estudiar en el taller}

1. El título y el núcleo argumental

2. Rafael Sánchez Mazas y la guerra civil

3. La novela y la película

4. El/La periodista

5. El buque-prisión "Uruguay" en el puerto de Barcelona

6. El viaje desde el puerto de Barcelona hasta el santuario

7. El santuario del Collell

8. Un soldado en el santuario

9. El fusilamiento

10. La huida

11.El soldado perseguidor

12.Los amigos del bosque

13. La búsqueda del soldado desconocido

\section{Estudio comparativo de las fuentes de documentación novela/filme}

\subsection{El título y el núcleo argumental}

Sánchez Mazas expresaba el futuro título de la nievela cuando, al narrar a los amigos del bosque lo que le había sucedido tras el frustrado fusilamiento, exclamó: "Algún día contaré todo esto en un libro: se titulará Soldados de Salamina." (Cercas, 2001, p. 53). El mismo título adoptó Cercas para su novela: "En fin lo que me gustaba del titulo es que su significado era ambiguo y puede explosionar en distintas direcciones" (Cercas, 2003, p. 145). 


\subsection{Rafael Sánchez Mazas y el escenario de la Guerra Civil}

La película ofrece documentación audiovisual elaborada ad hoc como la visión de sus obras y recortes de prensa y la entrevista con su hijo (20.40/22.59), así como el documental de época donde se recoge su toma de posesión como ministro (34.15/36.37).

De modo similar, la película permite mostrar los aportes documentales que contienen imágenes de la época -José Antonio Primo de Rivera, elecciones de 1936, el golpe militar (39.40/40.25) - y de los combates en la guerra (7.42/10.40).

\subsection{La novela y la película}

El relato es parte de una biografía -la del escritor-, pero también es biografía del hipotético y anónimo soldado que no quiso disparar en el último momento y que parece personaje de ficción. Así pues, la novela y la película se mueven en el borde entre lo real y lo falso, entre lo histórico y la ficción y sobre este filo se mueve el escritor/periodista, auténticamente implicado en el relato, como un protagonista, visto por Cercas (2003, p. 21) y por Trueba como sigue:

La novela No habla, fundamentalmente, de la guerra civil [...] La novela, básicamente, habla de los héroes, de la posibilidad del heroísmo; habla de los muertos y del hecho de que los muertos no están muertos del todo mientras haya alguien que los recuerde.

\subsection{El /la periodista}

Como hemos indicado, el autor del relato participa como narrador en primera persona y y se siente implicado en las emociones y sentimientos que de aquel se desprenden. En la película, la narradora Lola Cercas, periodista.

\subsection{El buque-prisión "Uruguay" en el puerto de Barcelona}

El 24 de enero de 1939, dos días antes de que las tropas de Yagüe entren en Barcelona, le despierta un rumor inusual, y no tarda en advertir el nerviosismo de los carceleros. Por un momento piensa que lo van a poner en libertad; al momento siguiente piensa que van a fusilarlo. La mañana transcurre entre esas alternativas angustiosas.

Video: El buque "Uruguay" en el puerto de Barcelona. Viaje en autobús hacia el santuario. Huida de civiles. Documental reconstruido (43.15/44.4).
6.6. El viaje desde el puerto de Barcelona hasta el santuario

La narración del novelista desde la vida en el barco hasta la llegada al santuario del Collell dejando a su paso la columna de población civil que huye hacia la frontera francesa del ejército franquista que avanza victorioso, es adaptado para la pantalla mediante la búsqueda de escenas que tratan de imitar y reconstruir un documental de la época (45.01/46.50).

\subsection{El Santuario del Collell}

Ya es noche cerrada cuando cruzan Gerona y más tarde Banyoles. Luego se internan por una empinada carretera de tierra que serpentea entre bosques en sombra, y al rato se detienen ante un macizo de piedra punteado de luces, como un descomunal galeón zozobrado en medio de la oscuridad envenenada por las órdenes urgentes de los carceleros. Es el santuario de Santa María del Collell. Allí Sánchez Mazas va a pasar cinco días junto a otros dos mil presos llegados de lo que queda de la España republicana, incluidos varios desertores rojos y varios miembros de las Brigadas Internacionales.

\subsection{Un soldado en el santuario}

Era muy joven, oyó Angelats que decía Sánchez Mazas. De tu edad o quizá más joven, aunque tenía una expresión y unos rasgos de adulto. Por un momento, mientras me miraba, creí que sabía quién era; ahora estoy seguro de saberlo... Uno de los que nos vigilaban cuando salíamos a pasear al jardín. Enseguida me fijé en él, y yo creo que él también se fijó en mí, o por lo menos eso es lo que se me ocurre ahora, porque en realidad nunca intercambiamos una sola palabra.

\subsection{El fusilamiento}

[Sánchez Mazas] piensa que no va a morir, que va a escapar. Piensa que no puede escapar hacia su espalda, Porque los disparos vendrán de allí; ni hacia su izquierda, porque correría de vuelta a la carretera y los soldados; ni hacia delante, porque tendría que salvar una muralla de ocho hombres despavoridos. Pero (piensa) sí puede escapar hacia la derecha, donde a no más de seis o siete metros un espeso breñal de pinos y maleza promete una posibilidad de esconderse. "Hacia la derecha», piensa. $Y$ piensa: «Ahora o nunca».

- Video: Imágenes de los presos tendidos sobre la tierra y el barro (1.08/2.10).

\subsection{La huida}

La narración, que transcurre entre la estancia de los presos en el santuario, el traslado hasta el lugar del fusilamiento, la escena del fusilamiento y la huida desesperada de Sánchez Mazas se basa en escasos testimonios documentales: el 
campesino (personaje real) que indica a la periodista el camino para llegar al lugar del fusilamiento, el mismo que ayudó a enterrar a los fusilados; el monumento erigido en memoria de los mismos y el bosque actual, sin duda con las mismas características de entonces. La película adapta con mucha fidelidad la narración y hace aparecer a los fusilados en el suelo, sobre el blanco, en sobrecogedoras imágenes en blanco y negro así como la huida de Sánchez Mazas, bajo la persistente lluvia, y atravesando el espeso boscaje hasta encontrar un lugar para ocultarse.

\subsection{El soldado perseguidor}

Entonces lo ve. Está de pie junto a la hoya, alto y corpulento y recortado contra el verde oscuro de los pinos y el azul oscuro de las nubes, jadeando un poco, las manos grandes aferradas al fusil terciado y el uniforme de campaña profuso de hebillas y raído de intemperie.... El soldado le está mirando; Sánchez Mazas también, pero sus ojos deteriorados no entienden lo que ven: bajo el pelo empapado y la ancha frente y las cejas pobladas de gotas la mirada del soldado no expresa compasión ni odio, ni siquiera desdén, sino una especie de secreta o insondable alegría...

Tratar de localizar al soldado anónimo que no quiso matar a Sánchez Matas e inquirír las razones por las que no lo hizo constituye el objeto de la segunda parte de la narración y de la película. Para Cercas, la causa de tal decisión es un gesto como contraste a la violencia de la guerra (Trueba, 2003, p. 140):

Lo que es cierto es que la guerra deshumaniza a la gente, en el sentido en que amparándose en ella, se legitima la violencia. Pero en medio de este infierno el hombre es capaz de un gesto, de recuperar durante un instante su condición humana.

- Video: Llegada al santuario por la noche. Llegada de la periodista. Visita al santuario. Los presos hacinados. Escenas del santuario. Marcha de los presos al lugar del fusilamiento. Aparece el soldado anónimo. Pregunta a un campesino por el lugar del fusilamiento.. El monumento. El fusilamiento. La huida de Sánchez Mazas. La periodista camina en paralelo. El soldado descubre a Sánchez Mazas. La periodista regresa (48.40/56.12, $2^{a}$ parte: 0/2.10)

\subsection{Los amigos del bosque}

Fue entonces cuando oyó que le daban el alto. Parándose en seco y levantando instintivamente las manos, distinguió a una distancia como de quince metros, destacándose apenas contra el verde confuso del bosque, tres figuras borrosas que empezaron a avanzar hacia él en actitud de expectativa y acecho. Se trata de los denominados amigos del bosque que van a acompañar y proteger a Sánchez Mazas hasta su definitiva liberación y que, parte de ellos o sus descendientes, han constituido fuentes orales de información para la elaboración de la novela y la película.

- Video: Entrevista para la obtención de los primeros datos (15.05/15.45).

- Video. Entrevista con el hijo de Figueras. Entrega del diario de Sánchez Mazas (31.28/33-0).

- Video. Entrevista con Angelats. Archivo Histórico de Gerona. Toma de posesión de Sánchez Mazas (34.15/36.37)

- Video. Entrevista con Figueras. Descripción de Sánchez Mazas. Anécdota: "Nos dijo que escribiría un libro” (37.10/38.39).

\subsection{La búsqueda del soldado desconocido}

Al final no se trataba tanto de dar con el Miralles real $\mathrm{Cmo}$ de encontrar a alguien con una historia similar a Miralles que interpretara a Miralles (Trueba, 2003, p. 123).

La afirmación de Trueba es el pórtico de inicio de la búsqueda de un auténtico excombatiente de la guerra de España que vive en una residencia de ancianos en Dijon (Francia). La película sigue el texto de la novela sobre la que construye las imágenes.

Son dos los diálogos de la periodista con Miralles entre los cuales tiene lugar el almuerzo de ella en un restaurante donde el camarero, hijo de un excombatiente, le enseña una foto en que aparece Miralles con un rostro muy semejante al del soldado desconocido.

- Video. Diálogo primero con Miralles. Minutos 41.30/43.00 (2a parte).

- Video. En el restaurante de Dijon. Minutos 44.28/45.20 (2a parte).

- Video. Diálogo final con Miralles. Minutos 46.56/52.12 (2a parte).

Al término de la experiencia del taller, parece oportuno proponer las siguientes consideraciones:

1. La propuesta de taller de lectura que hemos expuesto es un instrumento que permite al estudiante percibir el contexto en el más amplio sentido de los hechos objeto de estudio y acostumbrarse a contemplar los mismos desde diversas perspectivas de las fuentes utilizadas por los autores, en este caso, un novelista y un cineasta.

2. La película dirigida por Fernando Truebas es una adaptación muy fiel de la novela de Ja- 
vier Cercas tanto en su desarrollo como en su filosofía. Participa del afán de documentarse del modo más profundo posible y de seguir fielmente el texto original; con frecuencia la película es transcripción cinematográfica de algunos pasajes de la novela. Se advierten, no obstante, algunos cambios que no afectan sustancialmente a lo dicho: en la película, el periodista es una mujer y hay una escena en el restaurante de Dijon que no aparece en la novela.

3. Las fuentes orales reales utilizadas en la novela aparecen con los mismos protagonistas. La película se enriquece, como es lógico, con documentales de la época o reconstruidos imitando el ambiente de época, como se ve en la huida de civiles hacia Francia.

4. Tanto la película como la novela dejan en el aire la posibilidad de haber hallado al soldado desconocido. En ambas se reconoce que los muertos de la guerra siguen viviendo en la medida en que son recordados y ambas reconocen en el gesto del soldado desconocido la bondad del hombre para sus semejantes en momentos decisivos.

5. La inclusión de la escena del restaurante de Dijon con la fotografía de excombatientes, en la que aparece la foto de Miralles, parece hacer prevalecer la tesis de la coincidencia con el soldado desconocido, aunque esta coincidencia solo pueden advertirla los espectadores de la película.

\section{Conclusiones}

La experiencia del taller que hemos presentado es una muestra que trata de avalar la eficacia del modelo expuesto en las páginas iniciales de este trabajo; o, de otro modo, se trata de aprovechar la metodología del comentario de textos como recurso didáctico para aprender a leer científicamente y, por consiguiente, a desarrollar la capacidad de investigación y de enseñanza en la formación de los intelectuales. La brevedad de este estudio no permite desarrollar todos los ítems contemplados en la metodología propuesta pero si nos ha permitido comprobar los siguientes extremos:

1. La metodología expuesta, dirigida a estudiantes de Documentación, se ha propuesto la selección y uso de las fuentes tal y como se manejan en los documentos expuestos, en este caso, la novela y la versión fílmica de la obra "Soldados de Salamina".

2. El estudio ha ofrecido la posibilidad de contemplar la tipología de las fuentes utilizadas en ambos documentos y, lógicamente, el distinto tratamiento que se ha ofrecido a ambas versiones de la obra.

3. La presencia de los textos y la correspondiente transcripción en imagen permite al alumno reflexionar sobre ambas perspectivas.

4. Finalmente, existen pruebas de que — tras el ejercicio y a través de las valoraciones personales solicitadas - el alumno ha logrado interesarse por el tema, profundizar en sus contenidos, conocer el contexto geográfico, histórico, literario, etc, en cuyo escenario se mece tanto la versión novelada como la fílmica, y prestarle elementos objetivos para que pueda formar criterio y formarse como intelectual, es decir, iniciarse o consolidarse en el oficio del pensamiento. Algunas de las valoraciones personales pueden verse en López Yepes, 2011b.

\section{Referencias}

Calleja, Seve (2006). Taller de Lectura. // Azorin. Castilla. Ed. de Inman Fox. Madrid: Espasa Calpe. 322-336.

Cercas, Javier (2001). Soldados de Salamina. Barcelona, Tusquets, 2001. http://centros.edu.xunta.es/iesvalada res/files/Soldados\%20de\%20Salamina-Texto.pdf. 91 p.

Cercas, Javier; Trueba, David (2003). Diálogos de Salamina: un paseo por el cine y la literatura. Ed. de Luis Alegre. Barcelona: Tusquets.

Finkel, Don (2008). Dar clase con la boca cerrada. Valencia: Universidad de Valencia.

López Yepes, José (2010). Cómo se hace una tesis: trabajos de fin de grado, máster y tesis doctorales. México, DF: Library Outsourcing Service, CUIB, UNAM.

López Yepes, José (2011a. La sociedad de la Documentación. Madrid: Fragua.

López Yepes, José (2011b). Dar clase con la boca cerrada. // Agustín Lacruz, C.; Ubieto Artur, I. Innovación y creatividad en Información y Comunicación. Zaragoza: Prensas Universitarias de Zaragoza. 207-221.

Trueba, David (2003). Soldados de Salamina. Película cinematográfica. www.youtube.com/watch?v=3x00wRAx J34, www.youtube.com/watch?v=-pDxaMZrZSo.

Wikipedia contributors (2012). Soldados de Salamina. // Wikipedia. Wikimedia foundation. http://es.wikipedia.org/wiki/Soldados de Salamina (201208-30).

Enviado: 2012-08-23. Versión corregida: 2012-2012-09-20. Aceptado: 2012-09-20. 